\title{
Membrane Separation Technology for Wastewater Treatment and its Study Progress and Development Trend
}

\author{
Jianwen Gao \\ College of Information Technology and Engineering, Marshall University, Huntington, WV, United States
}

\begin{abstract}
This paper introduced the definition and characteristic of membrane separates technology. Stated several conditional methods such as micro filtration, reverse osmosis, ultra filtration, nanofiltration, electro dialysis, liquid membrane, etc. Prospected the development of membrane separation technology.

KEYWORD: Membrane separation technology; Wastewater treatment
\end{abstract}

\section{INTRODUCTION}

The traditional water treatment technology has the disadvantages of low separation efficiency, high energy consumption and strict requirement of water temperature. The appearance and development of membrane separation technology have well solved these problems. In the membrane separation process and material without phase change, separation coefficient is larger, operating temperature at around room temperature, these advantages the becomes an important new technology to solve the contemporary mankind facing the energy, resources, environment and other major issues, and now many membrane separation technology can be applied widely, such as microfiltration, reverse osmosis and ultrafiltration, nanofiltration, electrodialysis, osmotic evaporation, liquid membrane and so on. Therefore, membrane separation technology has been recognized as one of the most promising technology in the late twentyfirst Century to mid twentieth Century [1-3].

\section{DEFINITION AND CHARACTERISTICS OF MEMBRANE SEPARATION TECHNOLOGY}

\subsection{The definition of membrane separation technology}

Membrane separation technology, as the name suggests, means a novel separation technique using a film which is specially manufactured and with selective transmission for separation, purification and concentration of the mixture driven by external force $[4]$.

\subsection{Characteristics of membrane separation technology}

(1) Low energy consumption. Because there is no phase change in the membrane separation process, energy consumption of the reverse osmosis is the lowest, which has considerable significance for overcoming the energy crisis in our country [5].

(2) The membrane separation process is carried out at room temperature, so it is especially suitable for heat sensitive substances, such as the separation, classification, concentration and enrichment process for heavy metals, chemicals and raw materials in the wastewater. For the treatment of drinking water with membrane method, the water quality of only depends on the nature of the film itself, such as the membrane pore size, membrane selectivity, there has nothing to do with the raw water quality [6].

(3) The application of membrane separation technology is very wide, it will not change the properties of substances during reaction process and no need for additives, so will not bring new pollutants and the wasting of other materials. It can be used for various types of wastewater treatment process.

(4) The separation devices of membrane separation method is very simple, easy to be operated and controlled, easy to maintain, has high separation efficiency. Compared with the conventional water treatment method, it has the advantages of small occupation area, high processing efficiency, etc. [7].

(5) Membrane separation technology equipment can achieve the standardization, automatic control, easy to be managed and run, which is also conducive to the development of industrialization $[8,9]$. 
3 COMMON MEMBRANE SEPARATION TECHNOLOGY AND ITS CHARACTERISTICS

Membrane separation technology has been widely used since it was invented, but the initial research and application of it are aimed at the field of water treatment. The current common membrane separa- tion process mainly includes microfiltration, ultrafiltration, nanofiltration, electrodialysis, reverse osmosis, liquid film, pervaporation etc. Different membrane separation technology has different separation mechanism and application range. Some common membrane separation processes are listed in Table $1[6-9]$.

Table 1 Some common membrane separation processes

\begin{tabular}{|c|c|c|c|}
\hline Membrane Process & $\begin{array}{l}\text { Membrane Pore } \\
\text { Size }\end{array}$ & Driven Force & Separation Mechanism \\
\hline Ultrafiltration & $0.05-1 \mu \mathrm{m}$ & pressure difference $0.1-1.0 \mathrm{MPa}$ & size and shape of molecules \\
\hline Reverse osmosis & $<1 \mathrm{~nm}$ & $\begin{array}{l}\text { static pressure difference } \\
1-10 \mathrm{MPa}\end{array}$ & selectivity of reverse osmosis membrane \\
\hline Electrodialysis & - & potential difference & selectivity of ion exchange membrane \\
\hline Osmotic evaporation & - & $\begin{array}{c}\text { chemical reaction and concentration } \\
\text { difference }\end{array}$ & $\begin{array}{c}\text { differences of solubility and diffusion } \\
\text { coefficient }\end{array}$ \\
\hline
\end{tabular}

\subsection{Microfiltration (MF)}

Microfiltration is a precise filtration process, as the same with reverse osmosis and ultrafiltration, they are all driven by pressure. The separated components are 0.1 to $0.2 \mu \mathrm{m}$ in diameter, mainly are fine microparticles, submicroparticles and nanoparticles. It is usually used for the terminal treatment of ultra pure water in the semiconductor industry, the first end pretreatment of the reverse osmosis. It was also used for the removal of microorganisms and odor impurities, etc. in the brewing of beer and other alcoholic drinks [6].

\subsection{Ultra filtration (UF)}

Ultrafiltration is similar to reverse osmosis, separating fractions with diameter of $0.005 \sim 10 \mu \mathrm{m}$, which is between the reverse osmosis and microfiltration. Reverse osmosis, ultrafiltration and microfiltration formed a membrane separation process from the ions to particles.

\subsection{Nanofiltration (NF)}

Nanofiltration membrane is a kind of pressure infiltration membrane with aperture between reverse osmosis and ultrafiltration membrane. It has a high retention performance for organic materials and high price, low price inorganic materials with molecular weight between 200 to 1000 . Nanofiltration is widely used for water softening, organic bio active substances and dechlorination, purification, concentration, wastewater decoloration. Studies on nanofiltration technology began at the end of the $1980 \mathrm{~s}$, though it is still in the laboratory research and development stage and there is no products on the market [8].

\subsection{Reverse osmosis (RO)}

Membranes with substances selectivity is called semipermeable membrane, generally, Membranes only permitting solvent go through but not for the solute are known as ideal semipermeable membranes. When the same volume of dilute solution (e.g. freshwater) and concentrated solutions (e.g. saline) were placed on both sides of a semipermeable membrane, the solvent of dilute solution will spontaneously flow to the side of concentrated solution, this phenomenon is named permeate as shown in Figure 1[7].

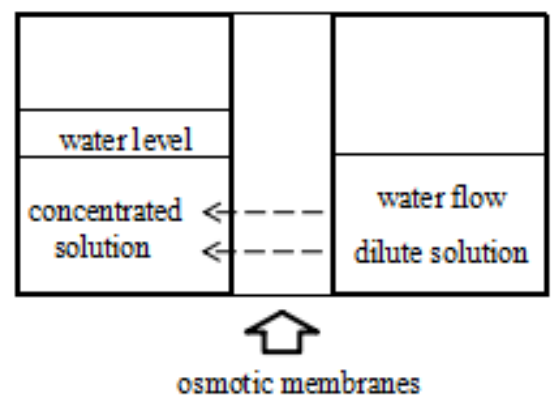

Figure 1 Schematic diagram of the osmotic membrane

When the infiltration process achieve balance, the liquid level of concentrated the solution side will be a certain higher than that of the dilute solution and there will format a differential pressure, known as the osmotic pressure. The value of osmotic pressure depends on the inherent nature of the solution, namely the solution species, concentration and tem- 
perature and there has nothing to do with the nature of the semipermeable membrane.

If a pressure greater than the osmotic pressure is added on side of the concentrated solution, the flow direction of the solvent will be opposite to that of the original direction, and it begins to flow from the concentrated solution to the side of the dilute solution, which is called reverse osmosis.

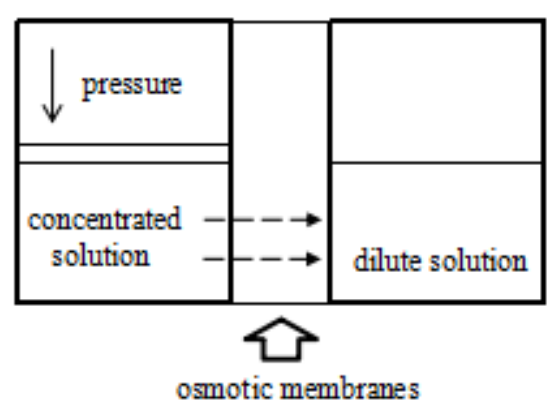

Figure 2 Schematic diagram of the reverse osmotic membrane

Reverse osmosis device work as the principle, water is pumped by high pressure booster, with the choice of semipermeable membrane interception function to remove inorganic ions in the water. Due to the reverse osmosis membrane in high pressure situations, it only allows water molecules to pass through and does not allow the potassium, the sodium, calcium, zinc ion and viruses, bacteria, so we can obtain high quality water.

\subsection{Electrodialysis (ED)}

Ion exchange membrane is the core of the electrodialysis. In presence of DC electric field, separating electrolyte from solution with the potential difference as the driving force and selective permeation of ion exchange membranes, achieving the solution desalination, concentration and passivation[10].

\subsection{Liquid membrane technology (LM)}

Liquid film usually consist of solvent, surfactant and additive. Two mutually non miscible liquid phases is made into emulsion by high speed stirring or other methods, then it was disperse into the third liquid phase as a result of the emulsion liquid membrane system forming.

\subsection{Osmotic evaporation (PV)}

Osmotic evaporation refers to the separation of two components by permeation and evaporation owing to the differences of solubility and diffusion coefficient between them in the liquid.

\section{APPLICATION PROSPECT OF MEMBRANE TECHNOLOGY}

The main direction of membrane separation technology in water treatment is drinking water production, material recycle in industrial water, reuse of water resources and the treatment of industrial waste water and so on. Large scale of the membrane and related processes, the monitoring and control of membrane fouling, the optimization of the operation conditions are also the main research directions [11].

The application of membrane technology in the field of environmental protection will become the development focus at home and abroad. Therefore, we put forward higher requirements for the membrane materials, especially should manufacture membrane materials adapting to the protection industry environment with high strength, long life, anti-pollution and high flux.

Any water treatment technology has its applicable scope, using only a kind of membrane technology will not necessarily be able to solve all the problem of water treatment. Therefore, usually different membrane technologies are used combined in practical application, each technology can give full use of their respective characteristics in this way with the result of greater technical and economic effects. The combination of membrane technology and the conventional water treatment technology also cannot be ignored, for example we can unite membrane technology, ion exchange and conventional filtration technology in the process of preparing high purity water, making use of each advantages, greatly improve the treatment efficiency, and also the processing cost is greatly decreased [12].

Membrane separation technology is developing rapidly, and the combination with other engineering science is also becoming more and more closely, such as the combination with sensor for membrane sensor, etc.. Membrane separation technology has been used more and more widely not only for conventional water treatment, but also for sterilization and other many fields. It can be expected that with the increasing improved regulations and standards, more mature membrane technology continued cost reduction, the increasingly rising price of water, there will appear a further improve for membrane water treatment technology and it should be more and more popular $[13,14]$.

\section{CONCLUSION}

As a new separation technology, Membrane separation has been widely used in many fields. It is one of the development direction of water treatment in the future. When applied to wastewater treatment, not only it has a good treatment effect, but also can be 
recycled and used to produce considerable economic, social and environmental benefits.

The main problem currently in membrane separation technology is membrane fouling, high price of membrane materials and the relatively short operational life span, which have limited the large-scale application of it to a certain extent. Along with the development of membrane separation technology, a variety of new membrane materials come out, the above problems will be solved, membrane separation technology will play an increasingly large role on the field of water treatment.

\section{REFERENCES}

[1] Manawi Y, Kochkodan V, Hussein M A, et al. Can carbonbased nanomaterials revolutionize membrane fabrication for water treatment and desalination?[J]. Desalination, 2016, 391:69-88.

[2] Pujawan N, Ciptomulyono U, Baihaqi I, et al. Design of a Total Productive Maintenance Model for Effective Implementation: Case Study of a Chemical Manufacturing Company[J]. Procedia Manufacturing, 2015, 4:461-470.

[3] Daer S, Kharraz J, Giwa A, et al. Recent applications of nanomaterials in water desalination: A critical review and future opportunities[J]. Desalination, 2015, 367:37-48.

[4] Wenten I G, Khoiruddin. Reverse osmosis applications: Prospect and challenges[J]. Desalination, 2015, 11(4):357358.

[5] Belaissaoui B, Claveria-Baro J, Lorenzo-Hernando A, et al. Potentialities of a dense skin hollow fiber membrane contactor for biogas purification by pressurized water absorption[J]. Journal of Membrane Science, 2016, 513:236-249.

[6] Thakur V K, Voicu S I. Recent advances in cellulose and chitosan based membranes for water purification: A concise review.[J]. Carbohydrate Polymers, 2016, 146:148-165.

[7] Zhang F, Gao S, Zhu Y, et al. Alkaline-induced superhydrophilic/underwater superoleophobic polyacrylonitrile membranes with ultralow oil-adhesion for high-efficient oil/water separation[J]. Journal of Membrane Science, 2016, 513:67-73.

[8] Liu J, Yuan J, Ji Z, et al. Concentrating brine from seawater desalination process by nanofiltration-electrodialysis integrated membrane technology[J]. Desalination, 2016, 390:5361.

[9] Yan F, Chen H, Yang L, et al. Improving the water permeability and antifouling property of thin-film composite polyamide nanofiltration membrane by modifying the active layer with triethanolamine[J]. Journal of Membrane Science, 2016, 513:108-116.

[10] Research and Application Status of Membrane Separation for Water Treatment[J]. Environmental Protection Science, 2006.

[11] Zhu H T, Wen X H, Huang X. Research Progress in Membrane Technologies for Water and Wastewater Treatment[J]. China Water \& Wastewater, 2007.

[12] Cao G P, Zhao P, Wen-Jie L I. Study Progress and Development Trend in Water Treatment Technology of the Membrane Separation Technology[J]. Water Conservancy Science \& Technology \& Economy, 2006.

[13] Jiang S J, Cheng-Yin D U. Application of Membrane Separation Technologyin Water \& Wastewater Treatment and Its Relative Priority[J]. Journal of Chongqing Architecture University, 2003.

[14] Jiang C C, Zhang J F. Progress and prospect in electroFenton process for wastewater treatment[J]. Journal of Zhejiang University - Science A: Applied Physics \& Engineering, 2007, 8(7):1118-1125. 